\title{
DISCLOSURE MANDATES FOR CONSUMER CREDITS DRAWN WITH PAYMENT CARDS: DOES IT HAVE SENSE? RUSSIAN PERSPECTIVE
}

\author{
Tatiana MIKONI \\ E-mail: t.mikoni@spbu.ru \\ Assistant Professor at the Faculty of Law, \\ Saint Petersburg State University
}

\begin{abstract}
It is commonly recognized that special legislation shall be crafted to regulate consumer credit and financial services. Disclosure mandates have always been considered the preferred method of regulation in comparison with the substantive restrictions. Russian law is no exception. Most of the provisions of the Federal Law No. 112-FL of 05 May 2014 on Consumer Credit deal with the information duties of financial institutions. The problem is that only a small part of these duties reflect the specific features of the credits drawn with payment cards. Considering the fact that these types of credit have become more popular in Russia ignoring of these features by a law maker can lead to dramatic consequences.

The purpose of the paper is to assess the effectiveness of disclosure mandates provided by the Federal Law No. 112-FL and, based on the results of such an assessment, propose possible changes to disclosure regulation which can improve the protection of consumers' rights.

The paper starts with a description of the features of credit drawn with payment cards which influence the consumers' ability to understand and use information. It proceeds with a general description of disclosure rules to give certain guidelines for further analysis of the provisions of Russian law. Then a detailed description of the disclosure mandates stipulated by the Federal Law No. 112-FL and applicable to credit cards and overdrafts is presented. The assessment of the current provisions and proposals for their improvement are provided in the final part of the paper.
\end{abstract}

Key words: consumer credit, consumer protection, payment card, overdraft facility, disclosure, informational asymmetry, bounded rationality. 


\section{Introduction}

Traditionally disclosure is considered to be the preferred method of consumer credit regulation because it allows market failures to be fixed and encourages competition without distorting markets. It is impossible to argue that disclosure is the perfect regulatory technique, yet it continues to play a central role in consumer credit regulation in many countries including Russia.

The specific feature of the Russian payment card market is that initially payment cards appeared mostly to facilitate transacting, not borrowing. Even today debit cards are much more popular than credit cards. Only one-seventh of all issued cards are credit ones (information is available on the official website of the Central Bank http://www.cbr.ru/statistics/nps/psrf/). This explaining why the specific features of the credits drawn with payment cards are almost completely overlooked by the lawmaker. However, this type of credit is becoming more popular so it should be considered.

This paper starts with a brief description of the different types of payment cards available in Russia. It proceeds with an outline of the features of the credit drawn with a payment card which are significant for drafting efficient disclosure rules. The second part of this paper explains the purposes of disclosure which predetermine the time and content of disclosure mandates. To navigate through the maze of the different types of disclosures, several categorizations are provided. The third part of this paper contains a detailed description of the rules provided by the Federal Law No. 112-FL of 05 May 2014 on Consumer Credit which is applicable to credits drawn with payment cards. The potential efficacy of each rule is assessed considering the specific features of this type of credit. The paper concludes by describing how disclosure mandates under the Federal Law No. 112-FL can be changed to improve consumer protection.

\section{Payment card as credit facility}

\subsection{Types of payment cards}

In Russia, three types of payment cards are available, debit card, credit card, and pre-paid card (paragraph 1.5 of Regulation No. 266-P of the Central Bank of Russian Federation of 24 December 2004 on the bank cards issue and transactions).

Debit card. The payment with a debit card can be made either using one's own money, if the balance is positive, or borrowed money, when the amount withdrawn from a bank account exceeds the available balance. The consumer uses only the card's transaction function as long as there are enough funds on the account. When the balance becomes negative, "the consumer uses the card simultaneously to transact and to borrow" (Muynck, M. De. (2010). p. 1183). 
Disclosure mandates for consumer credits drawn with payment cards...

If in accordance with the account agreement the bank makes a payment transaction even when there is not enough money on the client's account, the bank is extending credit to the client (Article 850 of the Civil Code of the Russian Federation). This type of credit is called overdraft. It is mostly regulated by the general rules about credit contracts. The main distinction between overdraft and regular credit is that overdraft shall always be part of the current account agreement. The contract with an overdraft facility is considered to bea mixed contract: both the rules for current account agreement and for credit contract are applicable.

Credit card ${ }^{1}$. Credit card transactions shall be funded using borrowed money within a certain limit provided in the credit contract (paragraph 1.5 of Regulation No. 266-P). When issuing a credit card, the bank and the client shall conclude a credit contract with a certain credit limit. The funds can be either credited to the client's account or paid directly to the payee. In the first instance, a current account agreement shall be also concluded between the bank and the client.

Pre-paid card. This type of card can be used only to transfer emoney. It is strictly forbidden by Russian legislation to increase an amount of e-money through consumer credit (Article 7 of Federal Law No. 161-FZ of 27 June 2011 on National Payment System (NPSL)). Consequently, there is no way for consumer to receive credit using pre-paid cards.

Based on these provisions, the consumer can borrow money either using a credit card or debit card with an overdraft facility. In spite of the differences in the types of contracts concluded in each case, similar consumer protection shall be provided in both cases. Two facts support this idea: (1) most of the credits drawn with payment cards are open-end revolving credits with credit limit; (2) borrowing with payment card results in specific features of the credit. As these features are important to assess the efficacy of disclosures, they should be considered in more detail.

\subsection{Specific features of consumer credit drawn with payment card}

First, there is always a time gap between the time a consumer negotiates terms of credit with the bank and actually uses the credit. When a consumer makes an agreement with a financial institution, he or she may have little intention to borrow. Although this is especially true for an overdraft facility, a credit card is also often considered to bea backup plan in case of emergency. This implies that when a consumer agrees to the terms of the contract he or she can actually pay no attention to them. If the consumer

\footnotetext{
${ }^{1}$ Usually, two types of cards are used as credit facilities: credit card and charge card. They are distinguished "in that a credit card balance can be rolled over... while charge card balance must be paid in full each billing period" (Rosenberg, A.S. (2006). p.525). Russian legislation does not make a difference between these two types of cards. Both of them are covered by a generic term - credit card.
} 
supposes that he or she will never borrow, or at least not borrow a lot, there is little incentive for him or her to spend time on learning the credit terms.

Second, "consumers are not always able to [distinguish] mere transacting from borrowing and credit therefore occurs unintentional, even unconsciously" (Muynck, M. De. (2010). p. 1212). Most of the clients do not check their balance regularly so consumers usually have no idea if they are using their own or borrowed money to pay the transaction. The fact that a credit card can be used only for payments funded with borrowed money does not make a huge difference. The client's current account used by the bank to provide credit can also be used by the client. Even if the client understands that the transaction is funded with borrowed money he or she can expect that there is enough money on the account to repay the debt on the due date.

Third, the changing nature of the credit makes it difficult to follow the total amount of the credit as well as the applicable rate. The revolving character of the credit implies that it can be repaid and drawn again from time to time. So, the client usually has no idea of the precise amount of credit at any specific moment. The situation is aggravated by rate changes. It can happen when either the rate is variable or the teaser rate has expired ${ }^{2}$. When different rates are applicable to different parts of the credit it becomes almost impossible for an average consumer to find his way through that maze of numbers.

These specific features of the credits drawn with payment cards significantly increase the risk that consumers will face cognitive limitations and biases. Such cognitive limitations can be easily exploited by financial institutions that not only know about the general cognitive biases but also have information concerning individual behavioral patterns of the clients. The former general counsel of one of Citigroup's card businesses noted that "no other industry in the world knows consumers and their transaction behavior better than the bank card industry. It has turned the analysis of consumers into a science rivaling the studies of DNA..." (Bar-Gill, O.; Warren, E. (2008). p. 24).

\footnotetext{
${ }^{2}$ Another common example of rate increase is when the financial institution initiates such a change. There is no direct prohibition in Russian law to change the rate. However, change of the rate shall be considered as amendment of the contract. In accordance with Article 310 of the Civil Code of Russian Federation, in the contracts with consumers the contractor can unilaterally amend a contract only if it is directly allowed by the law. To avoid that prohibition the banks provide in the contracts that the rate can be changed by an agreement of the parties which is concluded if the client has not rejected the new terms, announced by the bank on official web-site, during certain period of time. Whether such contract provision is legal or not is a very big question (Ivanov, O.M. (2019), p. 890).
} 
Disclosure mandates for consumer credits drawn with payment cards...

\section{Disclosure as regulating method}

Disclosure laws require one party of the contract to give information about products or services offered by the disclosure party to another party (Benoliel, U., Buchan, J., Gutentag, T. (2017). p. 469). The mandatory disclosure is considered as "the dominant form of regulation when it comes to consumer borrowing” (Edwards, M.A. (2014). p. 64).

The disclosure rules are based on the presumption that once a consumer has complete information about the product or service, he or she is able to make rational decisions choosing between different products and services as well as about making a contract. The proponents of disclosure regulation presume that a well-informed consumer is able to take a rational well-balanced purchase decision. The main advantage of the disclosure, in comparison with measures of substantive consumer protection, is that this method of regulation minimizes market interference, thus not hindering selfregulation and freedom of contract.

Effectiveness of disclosure for consumer protection has been criticized so many times that it seems that no one still believes in its magical power to remedy market failures (for comprehensive analysis of reasons why disclosure does not work see Ben-Shahar, O., Schneider C.E. (2014)). The main argument of the opponents is that consumers suffer from bounded rationality and are "therefore cognitively incapable of reading and analyzing disclosures, which are normally too complex and ubiquitous" (Benoliel, U., Buchan, J., Gutentag, T. (2017). p. 471). Despite this, most of the regulators still prefer disclosure to any other method of regulation. The Russian lawmaker is not an exception.

Since there is no chance that disclosure will cease to play a central role in consumer finance regulation in the near future, researchers have shifted the focus from criticizing disclosure to searching for ways to improve the effect of disclosure on the consumer's behavior (see, for example, Birkinshaw, C. (2005), Long, J. (2008), Muynck, M. De. (2010), Bar-Gill, O.; Bubb, R. (2012), Busch, C. (2019)). This positive approach shall be encouraged and extrapolated to Russian reality.

\subsection{Purpose of disclosure}

"[Disclosure is not an end itself but is deemed to mitigate market failures as well as individual shortcomings" (Muynck, M. De. (2010). p. 1223). This can be done only by influencing consumer behavior. So the efficacy of disclosure provisions can be estimated on the basis of desirable changes in consumer behavior caused by information supplied to them due to disclosure mandates. The degree of the desired influence can differ significantly: from simply providing information which is expected to be rationally used by consumers to changing the decision-making process in a more optimal way by implementing 'nudges' (for analysis of nudging as a 
regulatory method for consumer credit see Ali, P.; Ramsay, I.; Read, C. (2014)).

In the case of the credit market, it is generally recognized that the difficulty of financial services excludes any chance that general disclosure could have any effect on consumer behavior. More deliberate and tailored disclosures are required to mitigate the behavioral biases suffered by consumers when they are making financial decisions.

It is also important to keep in mind that the efficacy of disclosure depends on consumers understanding information and their ability to use this information to make a financial decision (Gillis, T.B. (2015). p. 36). This means that consumers should have enough knowledge, desire, and time to read and understand information as well as to apply it.

\subsection{Classification of disclosures}

Based on the purported effect of the disclosure, it is possible to distinguish between pre-contractual and post-contractual disclosures. When the purpose of disclosure is to affect the consumer's decision to acquire a product as well as to choose between different types of products, then disclosure should take place before the transaction (pre-contractual disclosure). When disclosure is designed to influence the consumer's ability to fulfill rights and obligations in accordance with the contract then disclosure can take place either before or after the transaction (post-contractual disclosure) (Whitford, C. W. (1973). p. 405).

This dichotomy is not strict and both types of disclosures may be considered to be parts of the single information regime (Muynck, M. De. (2010). p. 1235). It is also obvious that one and the same information can be relevant to the consumer when he or she concludes a contract and when he or she fulfills the contract. For example, it is essential to know rates and fees to choose the right credit product, but it is no less significant to remember this information to minimize the costs of payment card use. However, the most precious part of this classification is the underlying idea that in order to influence the consumer's decision-making process information shall be supplied to him or her at the moment when such information is relevant to make a decision.

Another categorization of disclosures is based on the content of information that is provided to consumer. Two categories of information can be distinguished - "information about product attributes" and "information about product use" (Bar-Gill, O.; Ferrari, F. (2010). p. 93). Product attribute disclosure requires revealing information about the inherent characteristics of the product or services. Product use disclosure, in turn, describes how use patterns influence the benefits and costs of the product or services. The product use disclosure can be categorized to proper-use disclosures, productattribute disclosure with average-use benchmarking, direct average-use 
Disclosure mandates for consumer credits drawn with payment cards...

disclosure, and individual-use disclosure (for the detailed description of all four categories of disclosures see Bar-Gill, O.; Ferrari, F. (2010)).

While this classification of disclosures is not strict, it means that traditional credit disclosures provide only product-attribute information which is hardly useful for the average consumer (Bar-Gill, O.; Bubb, R. (2012). p. 1003). That happens because consumers are assumed to know their wants and needs better and, consequently, to anticipate future use of the product. This is far from being true, especially in terms of financial services where financial institutions can often predict consumer's use patterns more accurately than the consumer him or herself (Bar-Gill, O.; Ferrari, F. (2010). p. 112).

\section{Disclosure rules in Russian consumer credit law}

Consumer credit is mostly regulated by special provisions of the Federal Law No. 353-FL of 21 December 2013 on Consumer Credit (CCL). In accordance with Article 3 of this law, consumer credit can be provided using the electronic payments facilities. The latter includes payment cards (paragraph 19 of Article 3 of NPSL). Consequently, if the opposite is not provided directly by CCL, all its provisions are applicable to credits drawn with credit and debit cards.

CCL relies not only on disclosure as a regulatory tool, but also puts several important limits on the terms of consumer credit contracts. For example, maximum APR is limited to one percent per day (paragraph 23 of Article 5 of CCL) and the penalty interest cannot be more than twenty percent per year (paragraph 23 of Article 5 of CCL). However substantive rules imposed by CCL are clearly in a minority in comparison with information duties provisions.

It is critical for understanding the meaning of disclosure provisions to mention that consumer credit contract consists of general terms and individual terms. General terms are determined by the financial institution unilaterally and are common for all borrowers (paragraph 3 of Article 5 of CCL). Individual terms shall be agreed personally with each borrower. If there is any inconsistency between general and individual terms the latter prevail (paragraph 10 of Article 5 of CCL).

For ease of presentation, all disclosures are divided between precontractual and post-contractual. However, this division is based not on the time when information is necessary for the consumer to make the right decision but rather on the time when it shall be provided in accordance with the law.

\subsection{Pre-contractual disclosures}

General terms. General terms of the contract together with twentyone other pieces of information shall be displayed at the places of services including the Internet (paragraph 4 of Article 5 of CCL, translated by the author). Theoretically, this means that any consumer at any time has access to 
such information and has an unlimited period of time to become aware of it. The problem is that this is far from reality. First, the general terms are too long and complicated for an average consumer. Second, this information is so general that it is almost useless. For example, it is usually provided that the amount of the credit can vary from one Ruble to several millions of Rubles and interest rates from 18 to 26 percent per year. It is very difficult to imagine how this kind of information can affect either the consumer's desire to order the payment card or his or her choice between different types of cards.

Individual terms. The financial institution shall provide individual terms to the consumer on his or her request by means of a standardized table prescribed by the Central Bank (paragraph 12 of Article 5 of CCL, translated by the author $)^{3}$. The text of the terms shall be clear and easy to read. After individual terms have been received by the consumer, he or she has at least five working days to accept the offer (paragraph 7 of Article 7 of CCL). Such period of time seems to be more than enough to read the terms which are presented in a standardized form from cover to cover. The problem is that almost no one does that. This can be because of insufficient literacy, complexity of the rules, or just simply lack of interest in gaining knowledge about the terms of the credit (Muynck, M. De. (2010). p. 1184).

Whatever the reason, it seems that most consumers think that it is not worth spending time and effort to read the general and individual terms ${ }^{4}$. This is especially true for the credits drawn with payment cards. As mentioned earlier, at the time the credit contract is concluded the consumer has very little incentive to study the rules. Even assuming that there is some chance to motivate consumers to read disclosures by providing more readable information (Benoliel, U., Zheng, X. (V.) (2018). p. 256) and increasing the level of their education (Reifner, U., Herwig, I. (2003). p. 137), it should be acknowledged that such information can influence only consumers' decision to conclude a contract. It would be unrealistic to assume that such disclosure can affect in any way consumer's use of the credit card or fulfillment of contract obligations.

Another problem is that all information contained in general and individual terms concerns attributes of the credit such as the amount of the credit, currency exchange rates, interest rates, liability provisions, etc. Even a

\footnotetext{
${ }^{3}$ The table, prescribed by the Instruction No. 3240-U of the Central Bank of Russian Federation of 23 April 2014, includes 16 points and is something between Schumer Box and Standard European Consumer Credit Information form set out in Annex II to Directive No. 2008-48/EC of the European Parliament and the Council of 23 April 2008 on credit agreements for consumers and repealing Council Directive 87/102/EEC.

${ }^{4}$ It would be interesting to check how many bank officers have read at least the most important terms offered by the bank and how many of them can explain the meaning of these terms. It can be assumed that the results will not be very encouraging.
} 
Disclosure mandates for consumer credits drawn with payment cards...

rational and well-educated consumer is barely able to estimate his or her future use of the payment card because there are many external factors influencing the consumer's wants and needs (Bar-Gill, O.; Ferrari, F. (2010). p. 96). Considering the fact that most of the consumers are far from being perfectly rational, the real effect of the general and individual terms disclosures is very limited.

The total cost of credit. The most promising disclosure provision is the obligation of the financial institution to inform the consumer about the total cost of credit (Article 6 of CCL). "The total cost of credit shall be placed in a square frame in the upper right corner of the first page of the consumer credit contract" (paragraph 1 of Article 6 of CCL, translated by the author). The frame shall occupy at least five percent of the total area of the page and the size of the font shall be the biggest on the page. The total cost of credit includes all payments and fees due under the credit contract. It seems that providing such information to the consumer is a perfect way to ensure comparison-shopping among financial institutions and credit products. Any consumer understands that "a lower score is better than a higher score" (BarGill, O. (2015). p. 76).

However, this is not easy when considering the credits drawn with payment cards. First, the total cost of the credit drawn with an electronic payment facility does not include fees associated with the usage of such a facility as well as stop-payment fees and foreign-currency-conversion fees (paragraph 6 of Article 6 of CCL). Transaction and service fees can significantly increase the consumer's expenditures but are not usually taken into account by him or her when choosing the product. Financial institutions can easily exploit limited rationality of consumers by decreasing the total cost of credit and increasing service and transaction fees to compensate for consequent loss.

Second, there is a special rule concerning how the total cost of credit shall be calculated in case of minimum monthly payment requirement, which is regular for credits drawn with payment cards ${ }^{5}$. The total cost of credit shall be calculated on the basis of the maximum amount of credit and the maximum time period required paying off the balance if only minimum payments were paid each month (paragraph 7 of Article 6 of CCL). The advantage of such disclosure is that it supplements product-attribute information with averageuse information. However, the efficacy of average-use disclosure is limited by consumers' optimism (Bar-Gill, O.; Ferrari, F. (2010). p. 117). Most of them believe that they are above average and will pay more than the minimum payment. Over-optimism might also cause consumers to think that they will never achieve a credit limit. The limited efficacy of the total cost of credit

\footnotetext{
${ }^{5}$ There is also a risk that minimum payments can be used to exploit consumers biases as myopia and over-optimism. However, this issue is outside the scope of the paper (see about this problem Muynck, M. De. (2010). 1207).
} 
disclosure for credits drawn with payment cards is exacerbated by the changing nature of this type of credit. It is likely that consumers will ignore this information as irrelevant.

Default warning. When a consumer asks for credit in the amount exceeding one hundred thousand Rubles, a financial institution shall inform him or her that the risk of default exists if during the year the total amount of all payments under all consumers' credits exceeds fifty percent of his or her annual income (paragraph 8 of Article 5 of CCL). Such warning could be useful if taken seriously by the consumer. But again, over-optimism about future incomes and underestimation of future borrowing cause most of the consumers to ignore the notice.

\subsection{Post-contractual disclosures}

Monthly statement. The creditor shall send to the consumer a monthly statement containing information about current credit balance, available credit limit, and the dates and amounts of the payments made during the previous month and the date and the amount of the next due payment (paragraph 2 of Article 10 of CCL). This individual-use information is hardly enough to enable the consumer to estimate his or her past borrowing patterns and to influence his or her future behavior. Quite the contrary, myopic consumers tend to be attracted by such short-term aspects of credit as available credit limit and the next due payment.

Default notice. The creditor shall inform the consumer of an overdue payment within seven days after the due date (paragraph 4 of Article 10 of CCL). For the very diligent consumer it maybe that such a notice is enough to induce him or her to pay off the debt. For others, it would be much more persuasive if the information about the late fee was included.

Transaction notice. The creditor shall notify the consumer of the current credit balance and available credit limit after each payment card transaction (paragraph 5 of Article 10 of CCL).

The main advantage of this type of disclosure is that it is delivered at the time of borrowing in contrast to disclosures at the time of contracting (Mann, R.J. (2006). p. 154). At that moment it is much more relevant to the consumer. However, the problem is that the consumer has already borrowed at the time information is supplied. Of course, it still can influence his or her decision about future borrowing but only for a limited period of time.

\section{Possible ways to improve efficacy of disclosures}

Based on this analysis, one can conclude that the disclosures mandated by the CCL are not perfect, at least when applied to credits drawn with payment cards, though perfect disclosure rules do not exist. However, it is more than practicable to make disclosure mandates much more effective with only slight changes. 
Disclosure mandates for consumer credits drawn with payment cards...

The provisions of the CCL have two main flaws: either information is given to the consumer at the wrong time, too early or too late, to affect his or her behavior or information is insufficient to induce the consumer to change his or her behavior ${ }^{6}$. In the last part of this paper, possible changes to existing rules which can facilitate the protection of consumer rights will be considered.

\subsection{Pre-contractual disclosure}

The efficacy of pre-contractual disclosure for credits drawn with payment cards is limited because of the time gap between when information is provided to the consumer and when it becomes relevant to him or her. The most dangerous terms of the contract become meaningful for the consumer only after the occurrence of some bad event, for example, default (Muynck, M. De. (2010). p. 1205).

This means that to increase the efficiency of the disclosure its relevance for the consumer at the time of the credit contract should be improved. One possible way to do this is to ask the consumer to make certain choices between different options. In that case, the close connection between transacting and borrowing functions of the payment cards can be used for the benefit of the consumer. For example, the consumer can be asked to choose between different transaction limits, cash advance limits, or even daily borrowing limits ${ }^{7}$.

The necessity of making such a choice may encourage the consumer to read at least a table with individual terms. To give additional incentive it may be useful to associate the selected option to be marked with special reference to appropriate parts of the terms. But the main advantage is that decisions, which can influence future borrowing, can be made at the same time as information is provided. For example, if the consumer understands that cash advance rate or fee is much higher than transaction rate or fee he or she can set a daily limit for cash advance at one thousand Rubles (approximately 15 EURO). Even if the consumer does not remember in the future about the difference in the rates, he or she is still safe from borrowing too much with a higher rate. It is standard practice for financial institutions to put different limits for payment card usage so it should not be difficult to identify the most significant of them and to include such a list in CCL.

\footnotetext{
${ }^{6}$ We recognize possible negative consequences of information overload and do not say that more information is always better. We just admit that specific pieces of information, provided to the consumer at the right moment, can influence his or her behavior.

${ }^{7}$ Setting such limits can also be used by consumers as precommitment device. Those of consumers who are aware of their imperfect self-control may seek "credit arrangement that would help them precommit to borrow less" (Bar-Gill, O.; Warren, E. (2008). 34).
} 


\subsection{Monthly statement}

It has already been said that information that shall be included in the monthly statement is not sufficient to influence consumer's behavior. However, the main problem is not just a lack of information, many creditors voluntarily provide additional information or it is easily available in Internetbanking, but a lack of information that can cause a consumer to estimate his or her borrowing patterns.

As correctly noted by Oren Bar-Gill and Franco Ferrari, "the most informative disclosure would combine price and use information in multiple dimensions" (Bar-Gill, O.; Ferrari, F. (2010). p. 15). Use information, whenever it is possible, shall be based on individual use data. Today, with all thetechnical possibilities available to financial institutions, this type of information is readily available. It will not be a significant burden on creditors since they accumulate and analyze such information for their own purposes, to assess the risks or to tailor a product offer. Often the creditor can predict future use of the payment card better than a consumer him or herself. So financial institutions shall "be obliged to take into account available data on the consumer's credit card usage for tailoring the information" (Busch, C. (2019). p. 316).

The simplest way to do that is to oblige the creditor to include in the monthly statement information about the total amount of accrued interests and fees for the previous month and the total amount of the accrued penalty fees including over-limit fees for the same period. It is also useful to notify the consumer once a year of total amounts of these expenses for the year. No matter how irrational a consumer is, an average consumer is greedy enough to start thinking about optimizing spending once he or she has learned the amount of money paid to the creditor. It may even be taken further and the creditor might be obliged to include in the monthly statement "the date by which a cardholder would pay its balance in full if it made no further purchases and continued to make equal monthly payments in an amount equal to the last monthly payment" (Mann, R.J. (2006). p. 159).

\subsection{Transaction notice}

Point-of-sale disclosures have great potential to resolve the confusion problem caused by the close connection between transacting and borrowing functions of the payment card. The main shortcoming of the transaction notice, stipulated by CCL, is that it is delivered too late. To affect the consumer's decision, it should be received by him or her before the transaction and it should contain information relevant to the consumer making such a decision. Ronald J. Mann has made an interesting proposal.

Cardholders should be told at the time of each transaction the amount of their credit line the amount of credit available at the time of the transaction, and the amount of any overlimit or other fees that would 
be charged for engaging in the transaction. In transactions that are authorized online with a contemporaneous electronic communication from the issuer, the relevant information could be transmitted to the merchant along with the authorization; the merchant's payment terminal could display the information to the cardholder before the cardholder finally approves the transaction. (Ronald J. Mann (2006) p. 162, emphasis added).

Such notice can be irritating for the consumer as hindering the transacting process if it is received too often. This can even cause the consumer to ignore the information and that is not desirable at all. The balance can be found when the notice is required only for transactions above some certain amount, for example, one thousand Rubles.

\section{Conclusion}

Disclosure mandates are far from being a perfect regulatory tool to protect consumers and prevent financial institutions from exploiting consumers' behavioral biases. Still, the current provision of CCL can be significantly improved.

Three types of amendments can be offered: (1) at the time of contracting the consumer shall be obliged to choose between different transaction and payment limits; (2) a creditor shall be required to include information about past borrowing patterns of the consumer in the monthly statement; (3) point-of-sale notice shall be delivered to the consumer before the transaction is finished.

These changes in the time and content of disclosures will make information more relevant to the consumer and, consequently, allow affecting his or her behavior in a positive way.

\section{Bibliography}

Ali, P.; Ramsay, I.; Read, C. (2014). Behavioural law and economics: Regulatory reform of consumer credit and consumer financial services. Common Law World Review, vol. 43, 298 - 343.

Bar-Gill, O. (2015). Defending (Smart) Disclosure: Comment on More than You Wanted to Know. Jerusalem Review of Legal Studies, 11, 75 - 82.

Bar-Gill, O.; Bubb, R. (2012). Credit card pricing: The card act and beyond. Cornell Law Review, vol. 97, no. 5, 967 - 1018.

Bar-Gill, O.; Ferrari, F. (2010). Informing consumers about themselves. Erasmus Law Review, vol. 3, no. 2. $93-120$.

Bar-Gill, O.; Warren, E. (2008). Making credit safer. University of Pennsylvania Law Review, vol. 157, no. 2, 1 - 102. 
Benoliel, U., Buchan, J., Gutentag, T. (2017). Revisiting the rationality assumption of disclosure laws: An Emperical Analysis. Hofstra Law Review, vol. 46, no. 2, $469-488$.

Benoliel, U., Zheng, X. (V.) (2018). Are disclosures readable? An empirical test. Alabama Law Review, 70(1), $237-257$.

Ben-Shahar, O., Schneider C.E. (2014). More than you wanted to know: the Failure of Mandated Disclosure.Princeton University Press.

Birkinshaw, C. (2005). Making disclosure meaningful: a proposal. Canterbury Law Review, vol. 11, 30 - 58.

Busch, C. (2019). Implementing personalized law: personalized disclosures in consumer law and data privacy law. The University of Chicago Law Review, vol. 86, no. 2, 309-332.

Edwards, M.A. (2014). The virtue of mandatory disclosure. Notre Dame Journal of Law, Ethics \& Public Policy, vol. 28, $47-77$.

Gillis, T.B. (2015). Putting disclosure to the test: toward better evidencebased policy. Loyola Consumer Law Review, 28(1), 31-105.

Ivanov, O.M. (2019). Kommentari ykstat'e 890 Grazhdanskogo kodeksa Rossiyskoy Federacii. Zaem, kredit, factoring, vklad I schet: postateyniy kommentariy $\quad k \quad$ stat'yam807 - 860.15 Grazhdanskogo kodeksa Rossiyskoy Federacii [Commentary on Art. 890 of the Civil Code of the Russian Federation. Loan, credit, factoring, deposit and account: article by article commentary on Articles $807-860.15$ of the Civil Code of the Russian Federation],edited by Karapetov A.G. Moscow: Statute.

Long, J. (2008). Navigating the Maze: Reviewing the information disclosure requirement in the financial services Acquis. European Business Law Review, vol. 19, issue 3, 485 - 524.

Mann, R.J. (2006). Charging ahead: the growth and regulation of payment card markets. Cambridge University Press.

Muynck, M. De. (2010). Credit cards, overdraft facilities and European consumer protection: a blank cheque for unfairness? European Review of Private Law, 18, 1181 - 1241.

Reifner, U., Herwig, I. (2003). Consumer education and information rights in financial services. Information \& Communication Technology Law, vol. 12, no. 2, $125-141$.

Rosenberg, A.S. (2006). Better than cash? Global proliferation of payment cards and consumer Protection Policy. Columbia Journal of Transnational Law, vol. 44. $520-601$.

Whitford, C. W. (1973). The functions of disclosure regulation in consumer transactions. Wisconsin Law Review, 400-470. 